\title{
Free Triiodothyronine Level Indicates the Degree of Myocardial Injury in Patients with Acute Myocardial Infarction

\author{
${ }^{1}$ Dr. Lalitha. R, ${ }^{2 *}$ Dr. G. Komala, ${ }^{3}$ Aravinth, ${ }^{4}$ Dr. Priya Senthilkumar
}

${ }^{1}$ Affiliated to the Dr. M.G.R. Medical University, Professor \& HOD, Department of Biochemistry, Govt. Kilpauk Medical College, Chennai-10, India

${ }^{2 *}$ Affiliated to the Dr. M.G.R. Medical University, Senior Assistant Professor, (Presently Associate Professor, Government Vellore Medical College, Vellore), Department of Biochemistry, Govt.Kilpauk Medical College, Chennai-10

${ }^{3}$ II MBBS student, Affiliated to the Dr. M.G.R. Medical University, Govt. Kilpauk Medical College, Chennai-10

${ }^{4}$ Affiliated to the Dr. M.G.R. Medical University, Associate Professor, Department of Preventive and Social Medicine, Govt. Kilpauk Medical College, Chennai-10

*Corresponding Author: Dr. G. Komala, Affiliated to the Dr. M.G.R. Medical University, Senior Assistant Professor, (Presently Associate Professor, Government Vellore Medical College, Vellore), Department of Biochemistry, Govt.Kilpauk Medical College, Chennai-10

Abstract: Inflammation implicated in the pathophysiology of acute myocardial infarction causes release of cytokines which disrupt the hormonal milieu. This leads to reduced circulatory levels of hormones like Triiodothyronine which cause worsening of the pathological remodelling of cardiac myocytes. Free T3 levels are implicated as prognostic markers after MI. This cross sectional study on 88 MI patients was conducted to correlate severity of myocardial damage as assessed by TropI, WMSI and hsCRP with Free T3 levels. Results revealed a negative correlation of hSCRP, Trop I and WMSI with FT3 levels indicating that as FT3 levels decrease myocardial injury is increased, though no statistical significance could be established, medical significance to be considered. The negative correlation and trend observed with decreasing FT3 levels and increasing concentrations of hSCRP, TropI and WMSI need intervention, though limited by small sample size.

Keywords: free triiodothyronine levels, myocardial injury, acute myocardial infarction,Wall Motion Score Index, Ejection Fraction, Inflammation, De-iodinases.

Abbreviations: AMI-acute myocardial infarction, CVD-Cardiovascular Diseases, ApoB/A-apolipoprotein B I apolipoprotein A ratio, fT3-free triiodothyronine, IL-6- interleukin-6, WMSI-Wall Motion Score Index, EFEjection Fraction, D- De-iodinases, TropI- Troponin I

\section{INTRODUCTION}

In India, 31.7\% of deaths occur due to MI. Incidence of cardiovascular diseases was about 7\% in 1970 and increased up to 32\% in 2011.[1] There is a relatively early age of CVD deaths in the developing countries compared with those in the developed regions of the world. [2]

Myocardial infarction is one of the leading health problems in the world and it is an outcome measure in clinical trials, observational studies and quality assurance programmes. The term acute myocardial infarction (MI) should be used when there is evidence of myocardial necrosis in a clinical setting consistent with acute myocardial Ischaemia as defined by the Global MI Task Force. [2]

Accoding to the interheart study, nine risk factors were significantly associated with acute $\mathrm{MI}$ in women and men including hypertension, diabetes, alcohol intake, physical activity, ApoB/A levels, current smoking, abdominal obesity, high-risk diet and psychosocial factors. [3]

Iervasi et al report a strong correlation between low free biologically active triiodothyronine (fT3), a thyroid hormone, and all-cause cardiovascular mortality in 573 consecutive patients with heart disease.[4], making low fT3 levels as one of the risk factors in predicting prognosis after MI.

Plasma triiodothyronine (fT3) is a strong predictor of adverse clinical outcomes in various clinical conditions and also associated with impaired endothelial function.[5] This adverse effect of low T3 levels is also seen on the heart in acute myocardial infarction, a consequence of atherosclerosis as both atherosclerosis and MI are inflammatory conditions. 
Inflammatory response acts as the bridge between AMI and hypothyroidism mediated by cytokines like IL-6. S.M.Wajner et al. found that, IL-6-induced oxidative stress decreases deiodinases D1-and D2-mediated T4-to-T3 conversion, but increases D3-mediated T3 [andT4] inactivation. [6]

Cardiac myocytes in the border zone of reperfused viable myocardium, as well as monocytes and macrophages in this area, produce IL-6, which mediate the changes in serum T3 level after an acute MI. Wagner et al proposed that rather than a protective or a maladaptive response, the changes in plasma levels of thyroid hormones are a consequence of cellular stress. [6]

Myocyte apoptosis is an important event after acute myocardial infarction. Thyroid hormones limit cardiac myocyte apoptosis under stressful conditions.

Thus, MI being an inflammatory condition causes a reduction in thyroid levels and this reduced thyroid level worsens the pathological cardiac remodelling, further worsening the condition of the heart. [7]

The assessment of left ventricular function following acute myocardial infarction is important from a prognostic point of view. Therapeutic studies have used global ejection fraction (EF) as assessed by either radionuclide ventriculography (RNV), echocardiographic LVEF alone or a combination of any of RNV, echocardiographic LVEF, ventricular angiographic LVEF as markers for LV dysfunction. [8]

More recently studies have used echocardiographic wall motion score index (WMSI) as a marker for LV dysfunction. Echocardiographic WMSI derived by grading the wall motion of individual myocardial segments and dividing the total score by the number of analysable segments, is a relatively easily obtained marker of global LV dysfunction after myocardial infarction. Galasko et al, identified that there is a $94-95 \%$ probability that two subjects, one with a clinically significant abnormality in RNV EF and one without, would be correctly discriminated by an echocardiographic WMSI. [8]

At mild LV dysfunction there is compensatory hyperkinesis of non-involved myocardium. This would limit the reduction in global $\mathrm{EF}$ resulting from akinesis of the infarcted muscle while not affecting the WMSI, with WMSI acting as a more precise measure of myocardial damage. [8]

The purpose of this study is to investigate whether the lower thyroid hormone level in acute myocardial infarction is associated with severity of myocardial injury, as evaluated by cardiac troponin I (cTnI), hsCRP and WMSI.

\section{Materials AND Methods}

This cross - sectional study conducted in the Departments of Biochemistry and Cardiology of Govt. Kilpauk Medical College, Chennai-10 comprised of 88 acute MI patients.

Patients were diagnosed to have MI based on the presence of chest pain, ST elevation on ECG, and Regional Wall Motion Abnormality on echocardiogram.

For the above cross sectional study, sample size was calculated with a precision or absolute error (d) of $10 \%$, SD- standard deviation of FT3 in MI, as obtained from a study by Wang Wen-Yao et al, as 0.47 [9] and standard normal variate $\mathrm{Z}$ which is 1.96 for $\mathrm{p}<0.05$ to be 84 subjects and $5 \%$ nonresponders were added. Hence a total of 88 patients was obtained.

The exclusion criteria were thyroid diseases history, therapy with amiodarone, thyroid hormone, glucocorticoids; interventional or surgical procedures performed within the last 3 months, patients who received radiographic contrast medium within 2 weeks before measurements, as these states were known to influence the parameters of the study.

The Institutional Ethics Committee of Govt. Kilpauk Medical College, Chennai-10, approved the study. $5 \mathrm{ml}$ of fasting venous sample was drawn from the antecubital vein under aseptic conditions after obtaining informed consent from all the study participants.

Serum was separated by centrifugation at $3000 \mathrm{rpm}$ for 10 minutes, aliquoted into 3 eppendorfs and stored at $-20^{\circ} \mathrm{C}$ until further analysis. 1st aliquot was utilized for:

Fasting Blood glucose, Urea, Creatinine \& hs-CRP measurements. 2nd aliquot was utilized for estimating Troponin I \& 3rd aliquot was utilized for estimating fT3, fT4 and TSH.

Biochemical analysis was performed in Autora -random access chemistry analyser with kits from Spinreact for hs-CRP and biosystems kits for Glucose, Urea \& Creatinine. Troponin I, fT3, fT4 and TSH were assayed by using biotron ELISA kits in a ELISA reader and washer. 
Free Triiodothyronine Level Indicates the Degree of Myocardial Injury in Patients with Acute Myocardial Infarction

All biochemical analyses were performed after calibration with calibrators from Roche and assessed by controls from Bio-rad.

WMSI was assessed by ECHOCARDIOGRAPHY with the following parameters:

$\mathrm{LVEF}=(\mathrm{EDV}-\mathrm{ESV}) / \mathrm{EDV}$

Where EDV=End-diastolic volume; ESV=End-systolic volume

WMSI scoring:

Visual/subjective

normal, hypokinetic, akinetic, dyskinetic

Semiquantiative WMS or WMSI

1. = normal

2. = hypokinetic, i.e. reduced endocardial excursion and wall thickening

3. = akinetic, absent endocardial excursion and thickening

4. = dyskinetic, systolic bulging with no thickening

WMSI $=$ Total score of segments/Total number of segments.

Statistical analysis was performed using SPSS package version 20. PEARSON's rank correlation was used for univariate analysis. The groups were compared using analysis of Variance $\& \mathrm{t}$ test and $\mathrm{p}$ value of $<0.05$ was considered significant for $95 \%$ Confidence interval.

\section{RESULTS}

This cross- sectional study comprising of 88 AMI patients with predominant males comprising $69 \%$ as compared to $31 \%$ females revealed the mean age of study population to be 53.3 years.(Table no:1)

Table1. Demography of study population

\begin{tabular}{|l|r|r|r|r|r|}
\hline BPM & \multicolumn{1}{|c|}{ N } & \multicolumn{1}{c|}{ Minimum } & \multicolumn{1}{c|}{ Maximum } & \multicolumn{1}{c|}{ Mean } & \multicolumn{1}{c|}{ Std. Deviation } \\
\hline AGE (years) & 88 & 29 & 87 & 53.30 & 10.084 \\
\hline SBP $(\mathrm{mm} . \mathrm{Hg})$ & 88 & 90 & 170 & 123.30 & 14.837 \\
\hline DBP $(\mathrm{mm} . \mathrm{Hg})$ & 88 & 60 & 100 & 80.45 & 9.211 \\
\hline PULSE RATE (BPM) & 88 & 63 & 118 & 83.27 & 11.850 \\
\hline
\end{tabular}

* BPM - beats per minute.

The mean value of EF \% was $50.39 \%$ with Wall motion score index of 1.39 indicating a normal to hypokinetic myocardium. Mean hs-CRP levels were $9.22 \mathrm{mg} / \mathrm{L}$, well above the reference range (RR) $(0-3 \mathrm{mg} / \mathrm{L})$ pointing to the inflammatory status of the disease. Mean Troponon I levels were 27.98 $\mathrm{ng} / \mathrm{ml}(\leq 0.5 \mathrm{ng} / \mathrm{ml}$ is considered normal).fT3 levels showed a mean of $3.6 \mathrm{pg} / \mathrm{ml}(\mathrm{RR}=2.3-4.2 \mathrm{pg} / \mathrm{ml}$.). fT4 and TSH were also within the normal reference ranges respectively (fT4 $\mathrm{RR}=0.76-1.9 \mathrm{ng} / \mathrm{dl}$., TSH RR=0.34-4.25 mIU/l ) \{Table no: 2$\}$

Table2. Markers of Myocardial Injury and Thyroid Hormones

\begin{tabular}{|l|r|r|r|r|r|}
\hline & $\mathrm{N}$ & Minimum & Maximum & Mean & Std. Deviation \\
\hline EF (\%) & 88 & 21 & 69 & 50.39 & 9.182 \\
\hline WMSI (ratio) & 88 & 1.1250 & 2.4000 & 1.394460 & .2393032 \\
\hline hsCRP (mg/L) & 88 & .2600 & 19.3000 & 9.223068 & 4.1531720 \\
\hline $\begin{array}{l}\text { TROPONIN I } \\
(\mathrm{ng} / \mathrm{ml})\end{array}$ & 88 & .1200 & 122.2000 & 27.980455 & 33.2107928 \\
\hline fT3 (pg/ml) & 88 & .0300 & 8.9300 & 3.629545 & 1.9701123 \\
\hline fT4(ng/dl) & 88 & .0800 & 6.1000 & 1.064659 & .8161882 \\
\hline TSH (mIU/l) & 88 & .1000 & 16.2900 & 1.784205 & 2.3236034 \\
\hline
\end{tabular}

EF\% showed a positive correlation with fT3 levels with $\mathrm{p}=0.099$, indicating that as fT3 levels rise EF $\%$ also rises. Though not Statisticaly significant, medical significance to be considered.(table no:3)

Table3. Correlation of Free triiodothyronine levels with Ejection Fraction \%

\begin{tabular}{|l|l|r|r|}
\hline \multicolumn{2}{|c|}{ Correlations } \\
\hline \multirow{3}{*}{ EF (\%) } & EF (\%) & Ft3 \\
\cline { 2 - 4 } & Sig. (2-tailed) & 1 & .177 \\
\cline { 2 - 4 } & $\mathrm{N}$ & 88 & .099 \\
\hline \multirow{3}{*}{ Ft3 (pg/ml) } & Pearson Correlation & .177 & 88 \\
\cline { 2 - 4 } & Sig. (2-tailed) & .099 & 1 \\
\cline { 2 - 4 } & $\mathrm{N}$ & 88 & 88 \\
\hline
\end{tabular}


Lalitha. $R$ et al.

A negative correlation was present when fT3 levels were analysed with WMSI indicating that as fT3 levels increased, WMSI decreased towards normal ( Score of 1 is normal ,2-hypokinetic,3-akinetic, 4 - dyskinetic).(Table no:4)

Table4. Correlation of Free triiodothyronine levels with Wall Motion Score Index.

\begin{tabular}{|c|c|c|c|}
\hline \multicolumn{4}{|c|}{ Correlations } \\
\hline & & Ft3 & WMSI \\
\hline \multirow[t]{3}{*}{ Ft3 (pg/ml) } & Pearson Correlation & 1 & -.122 \\
\hline & Sig. (2-tailed) & & .257 \\
\hline & $\mathrm{N}$ & 88 & 88 \\
\hline \multirow[t]{3}{*}{ WMSI (ratio) } & Pearson Correlation & -.122 & 1 \\
\hline & Sig. (2-tailed) & .257 & \\
\hline & $\mathrm{N}$ & 88 & 88 \\
\hline
\end{tabular}

A negative correlation exists between fT3 levels and hsCRP and Troponin I (Table no: 5\&6 respectively).

Table5. Correlation of Free triiodothyronine levels with hsCRP levels

\begin{tabular}{|l|l|r|r|}
\hline \multicolumn{3}{|c|}{ Correlations } \\
\hline \multirow{3}{*}{ Ft3 $(\mathrm{pg} / \mathrm{ml})$} & Pearson Correlation & Ft3 & \multicolumn{1}{|c|}{ HsCRP } \\
\cline { 2 - 4 } & Sig. (2-tailed) & 1 & -.164 \\
\cline { 2 - 4 } & $\mathrm{N}$ & 88 & .127 \\
\hline \multirow{3}{*}{ hsCRP (mg/L) } & Pearson Correlation & -.164 & 88 \\
\cline { 2 - 4 } & Sig. (2-tailed) & .127 & 1 \\
\cline { 2 - 4 } & N & 88 & 88 \\
\hline
\end{tabular}

Table6. Correlation of Free triiodothyronine levels with Troponin I levels.

\begin{tabular}{|c|c|c|c|}
\hline \multicolumn{4}{|c|}{ Correlations } \\
\hline & & Ft3 & TROPONIN I \\
\hline \multirow[t]{3}{*}{ Ft3 (pg/ml) } & Pearson Correlation & 1 & -.174 \\
\hline & Sig. (2-tailed) & & .106 \\
\hline & $\mathrm{N}$ & 88 & 88 \\
\hline \multirow{3}{*}{$\begin{array}{l}\text { TROPONIN I } \\
(\mathrm{ng} / \mathrm{ml})\end{array}$} & Pearson Correlation & -.174 & 1 \\
\hline & Sig. (2-tailed) & .106 & \\
\hline & $\mathrm{N}$ & 88 & 88 \\
\hline
\end{tabular}

For better comparison, the study population was divided into 3 groups based on the fT3 levels as follows:

Group $1-<1.5 \mathrm{pg} / \mathrm{ml}-16$ patients $(\mathrm{n}=16)$

Group $2-1.5-4.2 \mathrm{pg} / \mathrm{ml}-42$ patients $(\mathrm{n}=42)$

Group 3 - >4.2 pg/ml - 30 patients $(\mathrm{n}=30)$

This was based on the reference value of fT3 being $1.5-4.2 \mathrm{pg} / \mathrm{ml}$.

Comparison among the groups revealed that the EF\% increased as the fT3 levels rose, though not statistically significant.(Table no:7)

Table7. Disaggregation data of EF\% by group

\begin{tabular}{|c|c|c|c|c|c|c|}
\hline \multicolumn{7}{|c|}{ Descriptives } \\
\hline \multicolumn{7}{|l|}{$\mathrm{EF}(\%)$} \\
\hline \multirow[t]{2}{*}{ GROUP } & \multirow[t]{2}{*}{$\mathrm{N}$} & \multirow[t]{2}{*}{ Mean EF \% } & \multirow[t]{2}{*}{ Std. Deviation } & \multirow[t]{2}{*}{ Std. Error } & \multicolumn{2}{|c|}{ 95\% Confidence Interval for Mean } \\
\hline & & & & & Lower Bound & Upper Bound \\
\hline Group1 & 16 & 48.13 & 12.099 & 3.025 & 41.68 & 54.57 \\
\hline Group2 & 42 & 50.86 & 8.418 & 1.299 & 48.23 & 53.48 \\
\hline Group3 & 30 & 50.93 & 8.578 & 1.566 & 47.73 & 54.14 \\
\hline Total & 88 & 50.39 & 9.182 & .979 & 48.44 & 52.33 \\
\hline \multicolumn{7}{|c|}{ ANOVA } \\
\hline \multicolumn{7}{|l|}{$\mathrm{EF}(\%)$} \\
\hline & & Sum of Squares & Df & Mean Square & $\mathrm{F}$ & Sig. \\
\hline \multicolumn{2}{|c|}{ Between Groups } & 100.104 & 2 & 50.052 & .588 & .558 \\
\hline \multicolumn{2}{|c|}{ Within Groups } & 7234.760 & 85 & 85.115 & & \\
\hline \multicolumn{2}{|c|}{ Total } & 7334.864 & 87 & & & \\
\hline
\end{tabular}


Free Triiodothyronine Level Indicates the Degree of Myocardial Injury in Patients with Acute Myocardial Infarction

WMSI, hsCRP and troponon I levels showed a decreasing trend with increasing fT3 levels. (table no :8 ), though no statistical significance.

Table8. Disaggregation data by WMSI, hsCRP \& Troponin I by group

\begin{tabular}{|c|c|c|c|c|c|c|c|}
\hline \multicolumn{8}{|c|}{ Descriptives } \\
\hline & & \multirow[t]{2}{*}{$\mathrm{N}$} & \multirow[t]{2}{*}{ Mean } & \multirow[t]{2}{*}{$\begin{array}{c}\text { Std. } \\
\text { Deviation }\end{array}$} & \multirow[t]{2}{*}{ Std. Error } & $\begin{array}{l}\text { 95\% Confidence } \\
\text { Interval for } \\
\text { Mean }\end{array}$ & $\begin{array}{l}95 \% \text { Confidence } \\
\text { Interval for Mean }\end{array}$ \\
\hline & & & & & & Lower Bound & Upper Bound \\
\hline \multirow{4}{*}{$\begin{array}{l}\text { WMSI } \\
\text { (ratio) }\end{array}$} & Group1 & 16 & 1.450781 & .3196831 & .0799208 & 1.621128 & 1.621128 \\
\hline & Group2 & 42 & 1.370536 & 2090706 & .0322603 & 1.435687 & 1.435687 \\
\hline & Group3 & 30 & 1.397917 & .2335558 & .0426413 & 1.485128 & 1.485128 \\
\hline & Total & 88 & 1.394460 & .2393032 & .0255098 & 1.445164 & 1.445164 \\
\hline \multirow{4}{*}{$\begin{array}{l}\text { hsCRP } \\
(\mathrm{mg} / \mathrm{L})\end{array}$} & Group1 & 16 & 10.240625 & 3.2422738 & .8105685 & 11.968311 & 11.968311 \\
\hline & Group2 & 42 & 9.486429 & 4.4811071 & 6914498 & 10.882840 & 10.882840 \\
\hline & Group3 & 30 & 8.311667 & 4.0482913 & .7391135 & 9.823323 & 9.823323 \\
\hline & Total & 88 & 9.223068 & 4.1531720 & .4427296 & 10.103041 & 10.103041 \\
\hline \multirow{4}{*}{$\begin{array}{l}\text { TROPONIN } \\
\text { I (ng/ml) }\end{array}$} & Group1 & 16 & 30.681250 & 39.5120786 & 9.8780197 & 51.735751 & 51.735751 \\
\hline & Group2 & 42 & 30.503810 & 32.5054623 & 5.0157017 & 40.633225 & 40.633225 \\
\hline & Group3 & 30 & 23.007333 & 31.1239294 & 5.6824261 & 34.629200 & 34.629200 \\
\hline & Total & 88 & 27.980455 & 33.2107928 & 3.5402824 & 35.017149 & 35.017149 \\
\hline
\end{tabular}

\begin{tabular}{|l|l|r|r|r|r|c|}
\hline ANOVA & \multicolumn{7}{|c|}{ Sum of Squares } & Df & Mean Square & F & Sig. \\
\hline \multirow{3}{*}{ WMSI } & Between Groups & .075 & 2 & .038 & .651 & .524 \\
\cline { 2 - 7 } & Within Groups & 4.907 & 85 & .058 & & \\
\cline { 2 - 7 } & Total & 4.982 & 87 & & & \\
\hline \multirow{3}{*}{ HsCRP } & Between Groups & 44.399 & 2 & 22.200 & 1.296 & .279 \\
\cline { 2 - 7 } & Within Groups & 1456.249 & 85 & 17.132 & & \\
\cline { 2 - 7 } & Total & 1500.649 & 87 & & & \\
\hline \multirow{3}{*}{ TROPONIN I I } & Between Groups & 1126.094 & 2 & 563.047 & .505 & .605 \\
\cline { 2 - 7 } & Within Groups & 94831.144 & 85 & 1115.661 & & \\
\cline { 2 - 7 } & Total & 95957.238 & 87 & & & \\
\hline
\end{tabular}

Disaggregation graphs were used to differentiate the 3 groups:

Disaggregation graphs clearly depicts the trend among the 3 groups divided based on fT3 levels indicating fT3 levels play a role in determing the magnitude of myocardial injury as indicated by the levels of EF\%, WMSI, hsCRP and tropinin I (graphs 1-4 respectively). Graph 5 depicts the levels of fT4 and TSH among the groups.

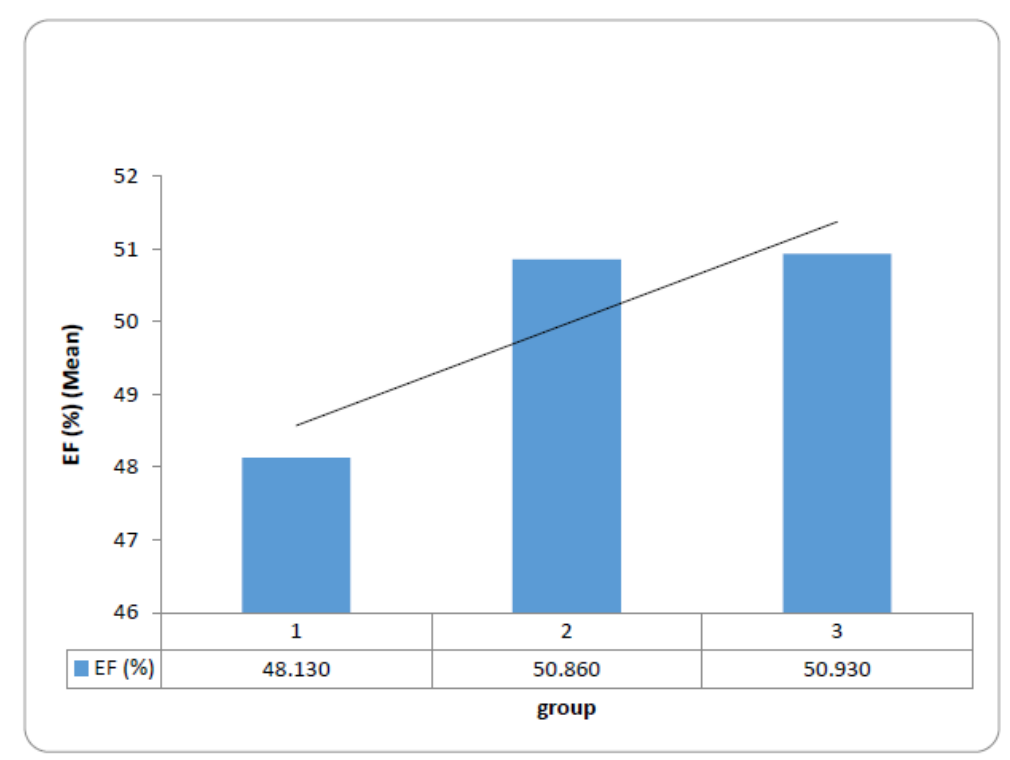

Graph1. Disaggregation graph of EF (\%) mean by group 


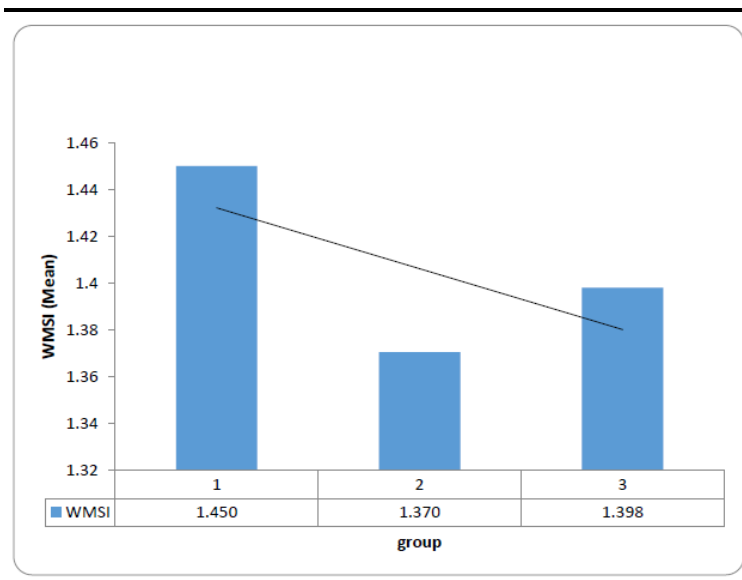

Graph2. Disaggregation graph of WMSI (mean) by group

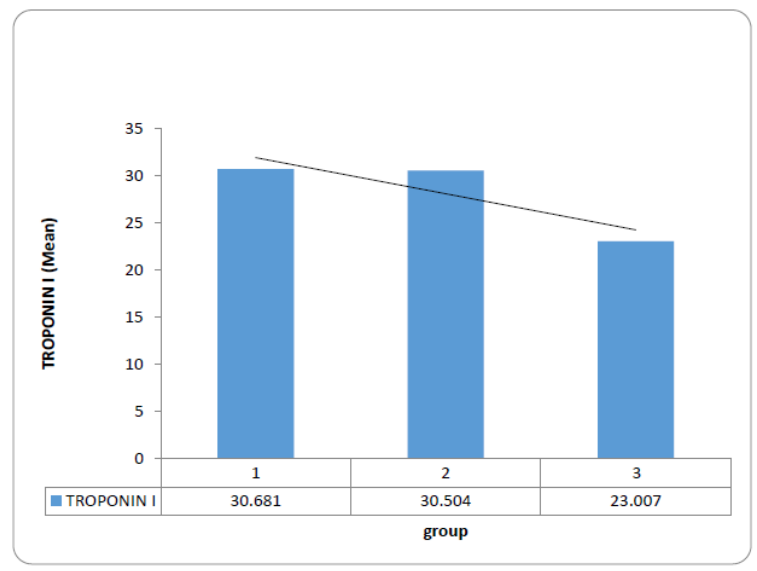

Graph4. Disaggregation graph of TROPONIN I (mean) by group

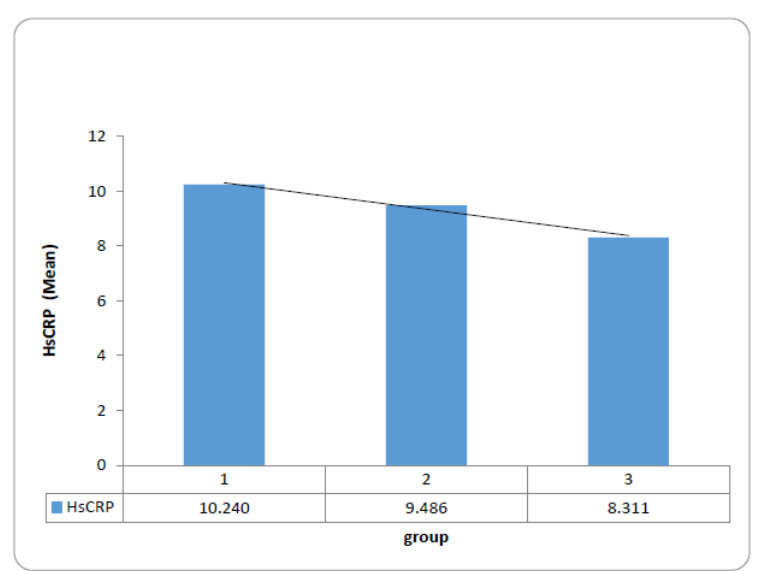

Graph3. Disaggregation graph of $H s C R P$ (mean) by group

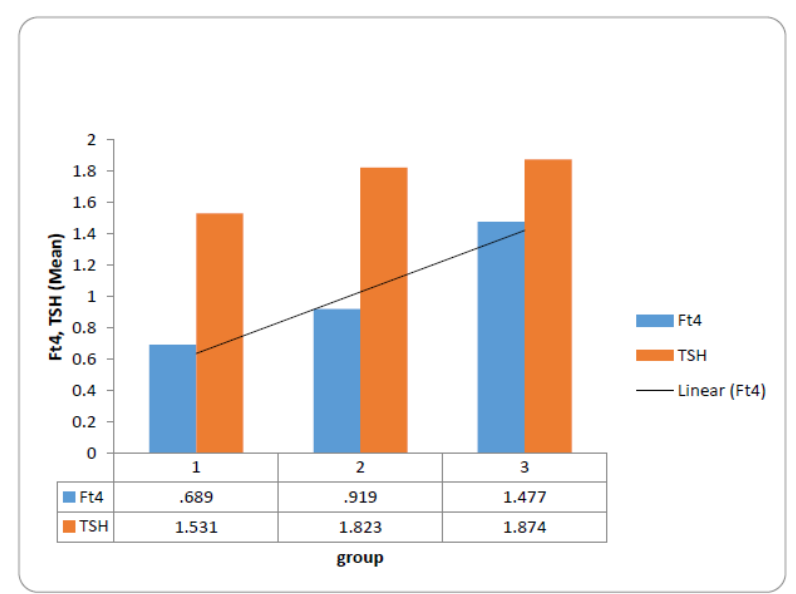

Graph5. Disaggregation graph of Ft4, TSH (mean) by group

\section{DisCUSSION}

The study was based on the hypothesis that free Triiodothyronine levels were reduced in acute myocardial infarction and this decrease could correlate with the degree of myocardial injury in such patients assessed by echocardiography with the aid of left ventricular ejection fraction (LVEF) and Wall Motion Score Index.

It is evident that $69 \%$ of the cases were males and $31 \%$ were females showing a clear 3:1 male preponderance. The interheart study also stated that male gender was a risk factor for MI. [3] the levels of hs-CRP and troponin I were very much elevated in all MI patients. Values of fT3, fT4 and TSH were with in the reference range for all patients.

To allow for a more clear understanding of comparison between fT3 levels and EF,

WMSI and Troponin I levels, the cases were divided into 3 groups based on reference range for fT3 and the findings were in accordance with hypotheses by Wang et al, that clearly showed an increase in EF with an increase in fT3 levels.[10] WMSI however increases when the fT3 levels go below 1.79 $\mathrm{pg} / \mathrm{ml}$ showing an increase in the regional wall motion abnormality as the cardioprotective mechanisms of fT3 decreases.

Similarly hs-CRP levels clearly show a reducing trend as we progress from group 1 to group 3 which is an order of increasing fT3 levels. This proves the inflammatory etiology of reduction in fT3 levels.

Myocardial infarction being an inflammatory state, Tatar et al, showed that fT3 levels are inversely associated with carotid atherosclerosis. Also, fT3 levels are inversely associated with surrogates of arterial stiffness in nondiabetics. [11] Several studies have suggested that low T3 levels are sensitive predictors of cardiovascular mortality in patients. $[12,13,14]$.

Leif Friberg et al proposed that cytokines were responsible for the alterations in thyroid hormone levels in myocardial infarction.[15] Corrsmit et al and Davis et al, showed that IL-6 and interferon 
alpha administration can induce changes in thyroid hormone system, thus confirming the hypothesis.[16] Inflammatory response may act as the bridge between AMI and hypothyroidism mediated by cytokines like IL-6. [6]

Graph 5 clearly shows that even when fT3 levels were below normal (group $1=<1.79 \mathrm{pg} / \mathrm{ml}$ ) the mean fT4 levels and TSH levels are perfectly within range. This is in accordance with the fact that AMI presents as Euthyroid Sick Syndrome and is often classified as Non-thyroidal Illness syndrome. $[17,18,19]$.

Robin P Peeters et al studied the peripheral metabolism of thyroid hormone in critically ill patients. In critical illness, serum T3 concentration decreases and serum rT3 increases, the magnitudes of these changes being related to the severity of disease. Although serum T4 and free T4 (FT4) may be increased in mild illnesses, serum T4 is decreased, and FT4 normal or decreased in severely ill patients. [20]

The strongly reduced circulating T3 levels in sick patients may be due to a decreased peripheral T4 deiodination by D1, D2, or both. The increase in serum rT3 levels is explained by a decrease in D1 activity because D1 is the principal pathway for rT3 clearance. Besides a decreased D1 activity, an impaired transport of T4 and rT3 into D1- containing tissues such as liver may be another important mechanism for the changes in thyroid hormone levels associated with illness. However, the possibility that an increased D3 activity contributes to the reduced serum T3 levels and increased rT3 levels should also be considered. [17]

Correlation of fT3 with TnI yielded a p value of 0.098 . Though this value of $p$ is statistically not significant there could be clinical significance as there was a increasing trend seen with troponin I concentrations, an indicator of myocardial injury, with decrease in fT3 levels,

This is true according to our hypothesis where T3 levels are reduced in severe inflammatory conditions. There are studies that state the cardio-protective function of T3. In a study by Nicolini et al, it is clearly stated that low Thyroid hormone is not simply a consequence of cardiac disease evolution but a permissive state that favours adverse cardiac remodelling and failure. [7]

Correlation of fT3 with EF - an indicator of myocardial function, yielded a p value of 0.099 , though close to significance but not. There was a clear increase in EF with increase in fT3 levels thus emphasizing the cardioprotective mechanisms.

Myocardial infarction, an inflammatory state predisposes to reduction of thyroid hormones which is just not only a consequence of heart disease but predisposes to adverse cardiac events. This novel finding needs therapeutic trails in the form of reduction of inflammation, which may lead to normalising thyroid hormone levels and its functions thereby altering prognosis of MI patients.

\section{Conclusion}

The study based on the hypothesis that inflammation causes reduction of thyroid hormones which inturn leads to severe myocardial injury, is assessed in the study by the parameters of hs-CRP, Trop-I, WMSI and EF\% .Though the study failed to establish statistical significance of data, clinical significance could not be excluded as, with fT3 levels, EF\% showed a positive correlation along with increasing trend and negative correlation with decreasing trend was observed for WMSI ,hs-CRP and Trpo-I, which all favour the hypothesis. The smaller sample size could have limited the statistical interpretation of data, which fact needs to be addressed by large clinical trails.

\section{FUNDING}

The study was funded by Indian Council of Medical Research, STS Grant No: Number 2014-02285

\section{ETHICAL APPROVAL}

All procedures performed in studies involving human participants were in accordance with the ethical standards of the institutional and/or national research committee and with the 1964 Helsinki declaration and its later amendments or comparable ethical standards."

Informed consent: Informed consent was obtained from all individual participants included in the study.

\section{REFERENCES}

[1] Pandey S, Pandey S, Jhanwar P, Jhanwar A. A prospective study of Myocardial Infarction patients admitted in a tertiary care hospital of south-eastern Rajasthan. Int J Biol Med Res. 2012; 3(2):1694-6. 
[2] Thygesen K, Alpert JS, Jaffe AS, Simoons ML, Chaitman BR, White HD, Katus HA, Apple FS, Lindahl B, Morrow DA, Clemmensen PM. Third universal definition of myocardial infarction. European heart journal. 2012 Oct 1; 33(20):2551-67.

[3] Anand SS, Islam S, Rosengren A, Franzosi MG, Steyn K, Yusufali AH, Keltai M, Diaz R, Rangarajan S, Yusuf S. Risk factors for myocardial infarction in women and men: insights from the INTERHEART study. European heart journal. 2008; 29(7):932-40.

[4] Iervasi G, Pingitore A, Landi P, Raciti M, Ripoli A, Scarlattini M, L'abbate A, Donato L. LowT3 syndrome. Circulation. 2003; 107(5):708-13.

[5] Yilmaz MI, Sonmez A, Karaman M, Ay SA, Saglam M, Yaman H, Kilic S, Eyileten T, Caglar K, Oguz Y, Vural A. Low triiodothyronine alters flow-mediated vasodilatation in advanced nondiabetic kidney disease. American journal of nephrology. 2011; 33(1):25-32.

[6] Wajner SM, Goemann IM, Bueno AL, Larsen PR, Maia AL. IL-6 promotes nonthyroidal illness syndrome by blocking thyroxine activation while promoting thyroid hormone inactivation in human cells. The Journal of clinical investigation. 2011; 121(5):1834-45.

[7] Nicolini G, Pitto L, Kusmic C, Balzan S, Sabatino L, Iervasi G, Forini F. New insights into mechanisms of cardioprotection mediated by thyroid hormones. Journal of thyroid research. 2013 Mar 10; 2013.

[8] Galasko GI, Basu S, Lahiri A, Senior R. A prospective comparison of echocardiographic wall motion score index and radionuclide ejection fraction in predicting outcome following acute myocardial infarction. Heart. 2001; 86(3):271-6.

[9] Zhang B, Peng W, Wang C, Li W, Xu Y. A low fT3 level as a prognostic marker in patients with acute myocardial infarctions. Internal Medicine. 2012; 51(21):3009-15.

[10] Wang WY, Tang YD, Yang M, Cui C, Mu M, Qian J, Yang YJ. Free triiodothyronine level indicates the degree of myocardial injury in patients with acute ST-elevation myocardial infarction. Chinese medical journal. 2013 Oct; 126(20):3926-9.

[11] Tatar E, Kircelli F, Asci G, Carrero JJ, Gungor O, Demirci MS, Ozbek SS, Ceylan N, Ozkahya M, Toz H, Ok E. Associations of triiodothyronine levels with carotid atherosclerosis and arterial stiffness in hemodialysis patients. Clinical Journal of the American Society of Nephrology. 2011; 6(9):2240-6.

[12] Ozen KP, Asci G, Gungor O, Carrero JJ, Kircelli F, Tatar E, Sevinc Ok E, Ozkahya M, Toz H, Cirit M, Basci A. Nutritional state alters the association between free triiodothyronine levels and mortality in hemodialysis patients. American journal of nephrology. 2011; 33(4):305-12.

[13] Carrero JJ, Qureshi AR, Axelsson J, Yilmaz MI, Rehnmark S, Witt MR, Bárány P, Heimbürger O, Suliman ME, Alvestrand A, Lindholm B. Clinical and biochemical implications of low thyroid hormone levels (total and free forms) in euthyroid patients with chronic kidney disease. Journal of internal medicine. 2007; 262(6):690-701.

[14] Zoccali C, Mallamaci F, Tripepi G, Cutrupi S, Pizzini P. Low triiodothyronine and survival in end-stage renal disease. Kidney international. 2006; 70(3):523-8.

[15] Friberg L, Werner S, Eggertsen G, Ahnve S. Rapid down-regulation of thyroid hormones in acute myocardial infarction: is it cardioprotective in patients with angina?. Archives of Internal Medicine. 2002; 162(12):1388-94.

[16] Corssmit EP, Heyligenberg R, Endert E, Sauerwein HP, Romijn JA. Acute effects of interferonalpha administration on thyroid hormone metabolism in healthy men. The Journal of Clinical Endocrinology \& Metabolism. 1995 Nov;80(11):3140-4.

[17] KAPTEIN EM, FEINSTEIN EI, NICOLOFF JT, MASSRY SG. Serum reverse triiodothyronine and thyroxine kinetics in patients with chronic renal failure. The Journal of Clinical Endocrinology \& Metabolism. 1983; 57(1):181-9.

[18] De Groot LJ. Dangerous dogmas in medicine: the nonthyroidal illness syndrome. The Journal of Clinical Endocrinology \& Metabolism. 1999;84(1):151-64.

[19] Warner MH, Beckett GJ. Mechanisms behind the non-thyroidal illness syndrome: an update. Journal of Endocrinology. 2010; 205(1):1-3.

[20] Peeters RP, Wouters PJ, Kaptein E, Van Toor H, Visser TJ, Van den Berghe G. Reduced activation and increased inactivation of thyroid hormone in tissues of critically ill patients. The Journal of Clinical Endocrinology \& Metabolism. 2003; 88(7):3202-11. 